\title{
Effect of the MEA design on the performance of PEMWE single cells with different sizes
}

\author{
Christoph Immerz • Martin Paidar . \\ Georgios Papakonstantinou . Boris \\ Bensmann* . Tomas Bystron . \\ Tanja Vidakovic-Koch · Karel \\ Bouzek • Kai Sundmacher • Richard \\ Hanke-Rauschenbach
}

Received: date / Accepted: date

\author{
B. Bensmann \\ Leibniz Universität Hannover, Welfengarten 1, D-30167 Hannover, Germany \\ Tel.: +49(0)511-762-14404 \\ E-mail: boris.bensmann@ifes.uni-hannover.de \\ C. Immerz \\ Leibniz Universität Hannover, Welfengarten 1, D-30167 Hannover, Germany
}

M. Paidar

Department of Inorganic Technology, University of Chemistry and Technology Prague, Technicka 5, Prague 6, 166 28, Czech Republic

T. Bystron

Department of Inorganic Technology, University of Chemistry and Technology Prague, Technicka 5, Prague 6, 166 28, Czech Republic

G. Papakonstantinou

Department Process Systems Engineering, Max Planck Institute for Dynamics of Complex Technical Systems, Sandtorstr. 1, D-39106 Magdeburg, Germany

T. Vidakovic-Koch

Department Process Systems Engineering, Max Planck Institute for Dynamics of Complex Technical Systems, Sandtorstr. 1, D-39106 Magdeburg, Germany

K. Bouzek

Department of Inorganic Technology, University of Chemistry and Technology Prague, Technicka 5, Prague 6, 166 28, Czech Republic

K. Sundmacher

Department Process Systems Engineering, Max Planck Institute for Dynamics of Complex Technical Systems, Sandtorstr. 1, D-39106 Magdeburg, Germany

H. Hanke-Rauschenbach

Leibniz Universität Hannover, Welfengarten 1, D-30167 Hannover, Germany 
Abstract In the field of polymer electrolyte membrane water electrolysis (PEMWE), a significant amount of excellent scientific results has been generated during the past decades. However, the comparability and reproducibility of these results between different cell types and different laboratories is not always straightforward. In this contribution, an exemplary ring experiment on the single-cell level compares the performances of three cell types: the differential cell $\left(4 \mathrm{~cm}^{2}\right)$ and two integral cells: an elongated cell $(50.4 \mathrm{~cm} \times 0.45 \mathrm{~cm})$ and a circular cell $(63.5 \mathrm{~cm})$. Therefore bi- and trilateral experiments were carried out with differently prepared catalystcoated membranes (CCMs) and porous transport layers (PTLs) as well as with an alternative catalyst-coated electrode (CCE) concept in three laboratories. This contribution aims to evaluate the grade of systemic inequality, which still permits a comparison of individual parameters.

The comparison of CCM preparation methods showed no significant influence on the initial electrochemical characteristics. An $\mathrm{HCl}$ etching of the anode PTLs in two different cells confirmed to be a useful treatment for the reduction of Ohmic losses in PEMWE cells. Self-made CCEs could not serve as an alternative concept, owing to their inadequate contact between the electrode and the membrane, which was observed in three laboratories as well. The general compatibility between the different cells was proven by the observation of a phenomenon in one laboratory that could be reproduced in one or two other laboratories. In this context, the size and geometry of the single cells did not influence the performance, indicating that up to the present measuring range and with sufficient water feed rates, the different single cells were functioning comparably.

Keywords PEM electrolysis · Ring experiment · Cell size variation · Validation of cell comparison

\section{Introduction}

The polymer electrolyte membrane water electrolysis (PEMWE) is widely discussed in science and industry as one of key elements to couple the energy vectors of future energy systems [1]. Scientific efforts throughout the last decades driven by a strong need towards the understanding of microscopic, macroscopic, and systemlevel phenomena resulted in a large number of published data. However, because of the wide variety of studies, reproducibility and comparability between two or more systems is crucial. Inevitable uncertainties can complicate a thorough assessment of experimental results in general. Experimental tests have been reported on material analysis (e.g., [2, 3]), operating conditions (e.g., [4, 5]), cell design (e.g., $[6,7])$, or the analysis of systematic phenomena (e.g., $[8,9]$ ), which are sometimes difficult to generalize without knowledge of the existing system constraints. Additionally, a well-known key issue for PEMWE is the scalability of these results from the microscopic to the system level (e.g., [10]). The deduction from microscopic phenomena with differential cells via spatially distributed cells of different geometries to the stack or the system level are of particular interest.

The aim of this contribution is to demonstrate that the comparison of experimental results up to a certain level of abstraction is feasible and necessary, even if particular constraints differ from each other. As a first approach, similar substantial cell components, catalyst-coated membranes (CCMs), porous transport layers 


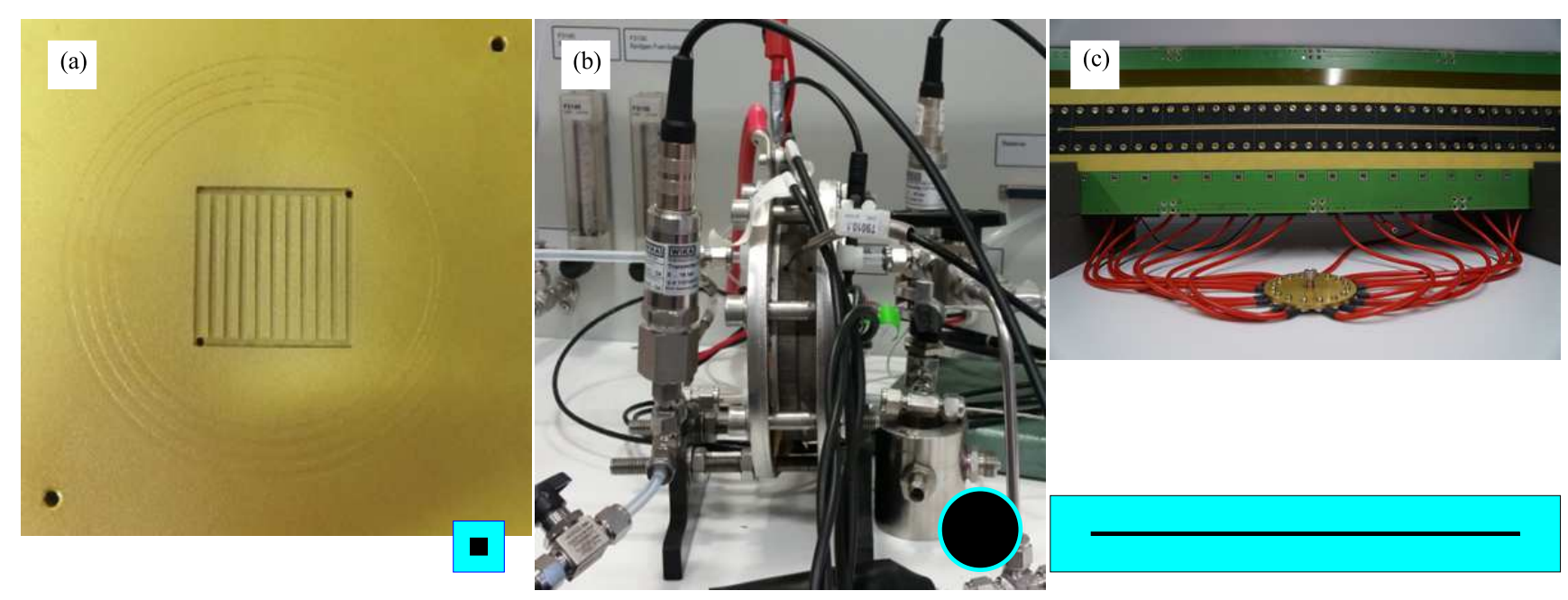

Fig. 1 Photos of the flow fields and cells used in the ring experiment with schematic sketches (scaled sizes) of the CCMs: black: active area, green: membrane (a) Cell $C 1\left(4 \mathrm{~cm}^{2}\right),(\mathrm{b})$ cell $C 2$ $\left(63.5 \mathrm{~cm}^{2}\right),(\mathrm{c})$ cell $C 3(50.4 \mathrm{~cm} \times 0.45 \mathrm{~cm})$

(PTLs), as well as catalyst-coated electrodes (CCEs) as an alternative to the $\mathrm{CCM} / \mathrm{PTL}$ combination were characterized in different laboratories with cells of highly dissimilar geometries: a quadratic differential cell $\left(4 \mathrm{~cm}^{2}\right)$ and two "integral" cells, a circular cell $\left(63.5 \mathrm{~cm}^{2}\right)$ and an elongated cell $\left(50.4 \mathrm{~cm} \times 0.45 \mathrm{~cm}=22.7 \mathrm{~cm}^{2}\right)$ as shown in Fig. 1. Within this framework, the effects detected in one of the partner's laboratories are checked for generality with the results from the other two laboratories. In both cases (accordance or divergence), the underlying reasons are observed and categorized as a general issue, or as a peculiarity of a special cell or measurement. Additionally, this ring experiment gives a first assessment as to what extent an obvious difference in the experimental setup impacts the measurement results and their comparability. Owing to the highly dissimilar geometries of the cells, ring experiments as such might be able to reveal challenging issues on a laboratory scale before stack assembly.

\section{Experimental}

\subsection{Introduction of lab measurement equipment}

In the following section, the different cell designs, test stations, and preparation methods are presented.

\subsubsection{Lab and cell C1}

An in-house-made single cell of square active area $2 \times 2 \mathrm{~cm}^{2}$ accommodated the parallel column distribution channels on both the anode and cathode sides serving for water distribution and gas removal, respectively. Titanium (Ti)-based end plates were gold plated. Eight bolts were localized around the end plates to ensure 
the desired compression force. The standard momentum torque $7 \mathrm{Nm}$ was applied to each bolt. Ti felt provided by Bekaert based on sintered fibers was used as the anode side PTL. Graphite-based nonwoven gas diffusion media GDL $34 B C$ provided by $S G L$ was used on the cathode side. The anode side PTLs will be discussed in more detail in Sec. 2.2. Three layers of expanded PTFE gasket of $0.5 \mathrm{~mm}$ thick (Gore) were used (two layers for anode and one layer for cathode). In CCM experiments, the active area of the membrane electrode assemblies (MEAs) was set by a square window cut in the PTFE gasket. Prior to cell assembly, the CCM was placed in $90^{\circ} \mathrm{C}$ hot demineralized water for 2 hours.

The electrochemical experiments were performed with the in-house-made test station, with which the temperatures of the cell end plates and the water inlet were controlled by PID controllers. The rate of water flowing through the cell was set to $25 \mathrm{ml} \mathrm{min}^{-1}$. The gravimetric gas/liquid separator with $250 \mathrm{ml}$ containers was used on the hydrogen and oxygen streams. PC-controlled stabilized power source Statron $18 \mathrm{~V} / 10 \mathrm{~A}$ was used to perform electrochemical experiments. For electrochemical impedance spectroscopy (EIS) measurements, the Solartron electrochemical interface 1287 and frequency response analyzer 1260 were used, with the power source disconnected from the cell.

\subsubsection{Lab and cell C2}

A Ti-based commercial single cell (Sylatech), of circular geometry $(9.1 \mathrm{~cm}$ diameter, $63.5 \mathrm{~cm}^{2}$ active area) was used for the electrochemical testing and tightened by $35 \mathrm{Nm}$ torque on each of the eight bolts. Porous Ti layers in the anode and hydrophobized carbon papers with a microporous layer in the cathode served as PTLs (34 BC, SGL). A Ti grid (Dexter, $900 \mu \mathrm{m}$ thickness) was used as a spacer in the anode to facilitate the reactants/products distribution. A PTFE gasket (120 $\mathrm{\mu m}$ thickness) in the anode and an O-ring in the cathode were used to prevent leakages. The overall compression of the layers without accounting for the compressible nature of the O-ring, was estimated to be $\geq 160 \mu \mathrm{m}$. The cathode plate accommodates one channel ( $4 \mathrm{~mm}$ width, $2 \mathrm{~mm}$ depth) orientated in the downward direction from inlet to outlet, to facilitate the removal of $\mathrm{H}_{2} \mathrm{O}$ permeated through the membrane. The anode flow configuration was counter flow with respect to the cathode.

A commercial test station from FuelCon (70460, Evaluator $C$ ) was used for the electrochemical testing, allowing the control and record of temperatures (inlets, outlets, and anode plate), pressures, $\mathrm{H}_{2} \mathrm{O}$ flow $\left(30 \mathrm{ml} \mathrm{min}^{-1}-150 \mathrm{ml} \mathrm{min}^{-1}\right)$ in the anode and $\mathrm{H}_{2}$ or $\mathrm{N}_{2}$ flow $\left(150 \mathrm{ml} \mathrm{min}^{-1}-250 \mathrm{ml} \mathrm{min}^{-1}\right)$ in the cathode, as well as the cell potential and current through a two-quadrant load $(30 \mathrm{~mA}-100 \mathrm{~A}$ range). The anode was pumped with high-purity $\mathrm{H}_{2} \mathrm{O}\left(95 \mathrm{ml} \mathrm{min}^{-1}\right)$, serving as both a reactant and a heating/cooling medium.

\subsubsection{Lab and cell C3}

The cell used in Lab3 is a conventional PEMWE cell but elongated in the flow direction with a single flow channel on the anode and cathode. As PTLs, Ti fiber felts from Bekaert were used to sandwich a CCM (respectively CCEs sandwiching a membrane). The main difference with regard to cell design is its elongated shape. The active area extends $50.4 \mathrm{~cm}$ in the channel direction but has a width of only 
$0.45 \mathrm{~cm}\left(A_{\text {geo }}=22.7 \mathrm{~cm}^{2}\right)$. The PTLs (respectively CCEs) were cut to the required size and framed into Teflon ${ }^{\circledR}$ flat gaskets. To guarantee the correct size of the active area, strips of catalyst inks were spray coated on a membrane $(8 \mathrm{~cm} \times 57 \mathrm{~cm})$ that are slightly wider and longer $(1 \mathrm{~cm} \times 52 \mathrm{~cm})$ than the active area. The wider catalyst areas were then covered by the gaskets and deactivated. This treatment was not required for the $\mathrm{CCE}$ concept. On the anode, a milled titanium plate with a channel $0.15 \mathrm{~cm}$ wide and $0.20 \mathrm{~cm}$ deep was displayed at the end plate on the anode. The cathode channel $(0.15 \mathrm{~cm}, 0.05 \mathrm{~cm})$ is milled in a poly carbonate, framed by the current and temperature measurement plates on either side. All cell components are sandwiched together and both half cells are connected with 34 screws each with a torque of $0.5 \mathrm{Nm}$ along the cell to realize a homogeneous contact pressure.

The test station E40 from Greenlight Innovations was used, which enabled the adjustment of demineralized anode inlet water flux of $45 \mathrm{ml} \mathrm{min}^{-1}$ and controlled the inlet temperatures. The cathode was purged with nitrogen prior to each experiment. The integrated power source, Sorensen DLM 5-75, can be used in both a potentiostatic or galvanostatic mode with a current range of $0.2 \mathrm{~A} \leq I_{\text {set }} \leq 75 \mathrm{~A}$ and a voltage range up to $U_{\text {set }}=5 \mathrm{~V}$. Furthermore an EIS measurement was performed with a Solartron Analytical ModuLab XM that was limited to a maximum current of $I_{\text {set,max }}=2 \mathrm{~A}$. The temperature inside the cell can be measured at the interface of the flow field and the PTL (respectively CCE) on the cathode side with 252 measurement resistors and controlled to a defined level. Owing to the unique geometry of the cell (manufactured by $S++$ Simulation Service), the temperature was controlled with 16 Peltier elements at the cathode and 16 heating elements on the anode. This guaranteed an isothermal temperature distribution in the cell. Additionally, the current density was measured along the channel by a printed circuit board system with 252 fine shunt resistors $\left(R_{\text {shunt }}=0.1076 \Omega\right)$.

Table 1 Overview of measurements carried out for the ring experiment. Matrix shows variation on preparation methods of two laboratories: P1, P2; cell geometries: $C 1$ - C3; electrodes: PTL1 - PTL4 + CCE

\begin{tabular}{|c|c|c|c|c|c|c|}
\hline & porosity, $\epsilon$ & $\begin{array}{l}\text { ode PTL/CCE } \\
\text { fiber diameter, } \delta\end{array}$ & treatment & $\begin{array}{c}C 1 \\
4 \mathrm{~cm}^{2}\end{array}$ & $\begin{array}{c}C 2 \\
63.5 \mathrm{~cm}^{2}\end{array}$ & $\begin{array}{c}C 3 \\
22.7 \mathrm{~cm}^{2}\end{array}$ \\
\hline PTL1 & $50 \%$ & $20 \mu \mathrm{m}$ & untreated & $P 1 / P_{2}$ & & $P 1$ \\
\hline PTL2 & $50 \%$ & $20 \mu \mathrm{m}$ & HCL-treated & P1 & & \\
\hline PTL3 & $80 \%$ & $25-40 \mu \mathrm{m}$ & HCL-treated & $P 1$ & & $P 1$ \\
\hline PTL4 & $80 \%$ & $25-40 \mu \mathrm{m}$ & untreated & & P2 & \\
\hline$C C E$ & $50 \%$ & $20 \mu \mathrm{m}$ & HCL-treated & $P 1$ & $P 1$ & $P 1$ \\
\hline
\end{tabular}

\subsection{Preparation of CCMs, CCEs and PTLs}

The investigated CCMs were prepared in two of the three laboratories to observe effects of slightly different preparation methods. The methods are called $P 1$ and $P 2$ and will be described in section 2.2.1 following. Catalyst coated electrodes were manufactured in Lab1 for use in experiments aiming to compare the influences of different MEA setups. Additionally, four anode PTLs of different structural 
properties or treatments were observed. The investigated materials, pretreatments, and preparation methods are presented in the following.

\subsubsection{Lab1: CCM, CCE preparation P1 and PTL treatment}

An airbrush technique was used for the catalyst layer depositions. To enhance the reproducible performance, a CNC airbrush machine controlled by a PC was used. Pt supported on carbon black HiSPEC 4000 (Alfa Aesar), 5 wt \% Nafion ${ }^{\circledR}$ emulsion in isopropanol (Nafion Store), isopropanol, and water were used for the cathode catalyst-ink preparation. For the anode ink Ir(IV)oxide $\left(\right.$ Premion $^{\circledR}$, Ir $84.5 \%$, Alfa Aesar), 5 wt \% Nafion ${ }^{\circledR}$ emulsion in isopropanol (Nafion Store), isopropanol, and water were used. For the anode catalyst layer, $15 \mathrm{wt} \%$ of Nafion $^{\circledR}$ binder while for the cathode catalyst layer $20 \mathrm{wt} \%$ of $N$ afion ${ }^{\circledR}$ binder were used. Both inks were spray coated on either membranes for CCMs or PTLs for CCEs.

For the CCE preparation, the anode and cathode catalysts were air brushed with ink directly onto the Ti felt or carbon paper, respectively. For the doublelayered Ti felt, the finer side was chosen for anode catalyst deposition. Each support ( $\mathrm{Ti}$ felt and GDL $34 \mathrm{BC}$ ) was heated up to $120^{\circ} \mathrm{C}$ before catalyst spraying. Elevated temperature ensures the fast evaporation of solvents and immobilization of catalyst. The presence of water in the ink is crucial to prevent the ignition of deposited catalyst. Multiple layers were deposited until the desired catalyst loading was attained. The catalyst load was controlled by weight increase after spraying each layer.

Catalyst-coated membranes were produced by spraying the catalytic inks directly on the membrane Nafion ${ }^{\circledR} 117$. Prior to the deposition, the membrane was purified by a common procedure [11] based on the activation in $60{ }^{\circ} \mathrm{C}$ of $3 \% \mathrm{H}_{2} \mathrm{O}_{2}$ and $0.5 \mathrm{moll}^{-1} \mathrm{H}_{2} \mathrm{SO}_{4}$. The activated membrane was placed on a vacuum bench and heated to $130{ }^{\circ} \mathrm{C}$. The anode catalyst layer of the desired Ir loading was deposited first. Subsequently, the membrane was flipped and the cathode side catalyst layer was deposited. In both cases multiple layers were deposited. The loading of the catalyst was estimated from catalyst ink consumption and the known efficiency of deposition. Finally, the prepared CCMs were cooled down and stored in dry form.

Furthermore, certain anode PTLs were pretreated in Lab1. Ti PTLs were etched in $60^{\circ} \mathrm{C}$ concentrated $\mathrm{HCl}$ for $5 \mathrm{~min}$ to remove the passive oxidation layer (Krýsa et al. [12] and Bystron̆ et al. [13]). Both types of anode PTLs experienced this treatment. The $\mathrm{Ti}$ felt of thickness $1 \mathrm{~mm}$, of fiber diameter $20 \mu \mathrm{m}$, and of porosity $50 \%$ was from Bekaert whereas the double-layered Ti felt of thickness $1 \mathrm{~mm}$, of fiber diameter 25 and $40 \mu \mathrm{m}$, and of porosity $80 \%$ was from Sylatech. An overview of the used anode PTLs is given in table 1.

\subsubsection{Lab2: $C C M$ preparation P2}

The CCMs of Lab2 were prepared by spraying the anode and cathode catalyst inks with air brush directly on a Nafion ${ }^{\circledR} 117$ membrane, with 178 um thickness ( Quintech), which was placed on a heated $\left(120^{\circ} \mathrm{C}\right)$ vacuum table. The membrane was dried at $130{ }^{\circ} \mathrm{C}$ and weighed in a humidity-controlled atmosphere before and after spraying to control the catalyst loadings. The cathode catalyst was always $60 \mathrm{wt} \%$ Pt supported on a high surface area carbon (Alfa Aesar), while in the anode, 
Ir(IV)oxide Premion $^{\circledR}$, Ir $84.5 \%$ min, Alfa Aesar) was used. The Pt-C loading was controlled at approximately $1.00 \pm 0.05 \mathrm{mg} \mathrm{cm}^{-2}$, while in the anodes the Ir loadings ranged between $(1.00 \pm 0.05) \mathrm{mg} \mathrm{cm}^{-2}-(1.50 \pm 0.05) \mathrm{mg} \mathrm{cm}^{-2}$. The catalyst inks were comprised of a mixture of catalyst, Nafion ${ }^{\circledR}$ ionomer suspension, and deionized water with different compositions, to provide for ionomer loadings of $15 \mathrm{wt} \%$ and $20 \mathrm{wt} \%$ on dry basis, in the anode and cathode, respectively. The ionomer suspension ( $5 \mathrm{wt} \%$ in $\mathrm{H}_{2} \mathrm{O}$ ) was prepared in house by rotary evaporation at $80^{\circ} \mathrm{C}$ under mild vacuum (350 mbar) of the original ionomer suspension ( 5 wt $\%$ in lower aliphatic alcohols, Quintech). The catalyst inks were initially dispersed under sonication and stirred overnight at $30{ }^{\circ} \mathrm{C}$ in a controlled $\mathrm{H}_{2} \mathrm{O}$ vapor saturated environment.

\subsection{Electrochemical characterization/test protocols}

The characterization of the CCMs and CCEs was performed with the following protocol, which was used by all groups. Polarization curves were recorded in the upward and downward directions with holding times of $10 \mathrm{~min}$ minimum for each step. Electrochemical impedance spectroscopy measurements were performed dependent on the cell and test station equipment, for the analysis of high-frequency resistances (HFR). All presented experiments were operated at temperatures of $T=60.0 \pm 2.5^{\circ} \mathrm{C}$ and ambient pressure.

In the framework of this ring experiment, the elaborated measurements are presented as an overview in table 1 . The entries differ in cell size, anode PTL porosity, fiber diameter, and PTL pretreatment as well as the preparation methods.

\section{Results and Discussion}

A comparison of three PEMWE cells of different geometries was realized in three laboratories. The following bi- and trilateral comparisons regarding the performance differences or similarities, are carried out to demonstrate the crucial aspects of this ring experiment.

\subsection{Influences of CCM preparation method}

The influence of differently prepared CCMs on the performance of a PEMWE cell was investigated. Therefore, CCMs prepared by methods $P 1$ and $P 2$ were tested in the differential cell $C 1\left(4 \mathrm{~cm}^{2}\right)$. Both catalysts were sprayed on Nafion ${ }^{\circledR} 117$ membrane and assembled with identical PTLs.

Polarization curves were measured for potentiostatic conditions at a constant temperature of $T=60{ }^{\circ} \mathrm{C}$ and a constant water flux of approximately $25 \mathrm{~g} \mathrm{~min}^{-1}$ at atmospheric pressure. The CCMs used for this test had a high catalyst loading of approximately $1.5 \mathrm{mg} \mathrm{cm}^{-2}$ of $\mathrm{IrO}_{2}$ on the anode and approximately $1.0 \mathrm{mg} \mathrm{cm}^{-2}$ on the cathode. The cathode $\mathrm{Pt}-\mathrm{C}$ loading of $1.0 \mathrm{mg} \mathrm{cm}^{-2}$ was used for all the experiments herein presented, and will not be mentioned in the further discussions.

The polarization data in Fig. 2 show that the performance of CCM prepared by method $P 2$ is slightly improved compared to the performance of $P 1$ CCMs. The 


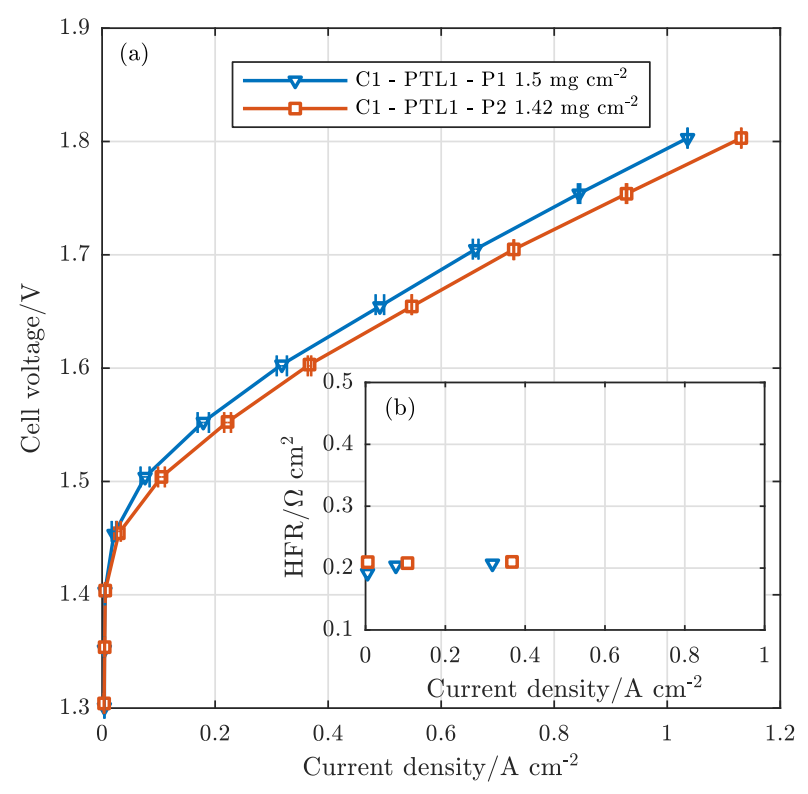

Fig. 2 Electrochemical characterization of CCMs prepared with two preparation methods $P 1$ and P2 with anode $\mathrm{IrO}_{2}$ loading of approximately $1.5 \mathrm{mg} \mathrm{cm}^{-2}$ and cathode Pt-C loading of approximately $1.0 \mathrm{mg} \mathrm{cm}^{-2}$. Both measured with cell $C 1\left(4 \mathrm{~cm}^{2}\right)$ under atmospheric pressure @ $60^{\circ} \mathrm{C}$ and an anode water flux of $25 \mathrm{~g} \mathrm{~min}^{-1}$. (a) Polarization curves (b) High-frequency resistances (HFR) for both CCMs

curve C1 - PTL1 - P2 (squares) of the CCM prepared with method P2 reaches higher current densities than the CCM $P 1$ for all set cell voltages. For example, for a current density of $i=0.1 \mathrm{~A} \mathrm{~cm}^{-2}$ the difference between the CCM P2 and $P 1$ is $\Delta U_{\text {cell }}=-22 \pm 2 \mathrm{mV}$.

For higher current densities $\left(i>0.1 \mathrm{~A} \mathrm{~cm}^{-2}\right)$, the difference between both curves remains almost constant $\left(\Delta U_{\text {cell }}=-20 \pm 2 \mathrm{mV}\right.$ for $\left.i=1.0 \mathrm{~A} / \mathrm{cm}^{2}\right)$. Additionally, Fig. 2 (b) shows the HFRs at different current densities. Solely for the lowest current density, slight differences in the HFR appear. These measurement data and the parallel slopes of the polarization curves for higher current densities indicate that the Ohmic resistances of both CCMs are similar, whereas the preparation method slightly influences the activation overpotential of the CCMs.

On the one hand, this appears reasonable since the Ohmic resistance depends on the quality of the electric contacting inside the cell, which was not modified among the experiments. On the other hand, the parallel slopes demonstrate that both preparation methods accomplish surprisingly well according to the ionic conductivity of the CCMs.

This analysis shows that the differences in the polarisation curve as well as in the HFR, are small enough to enable the clear identification of other influencing factors, discussed in detail in the following. 

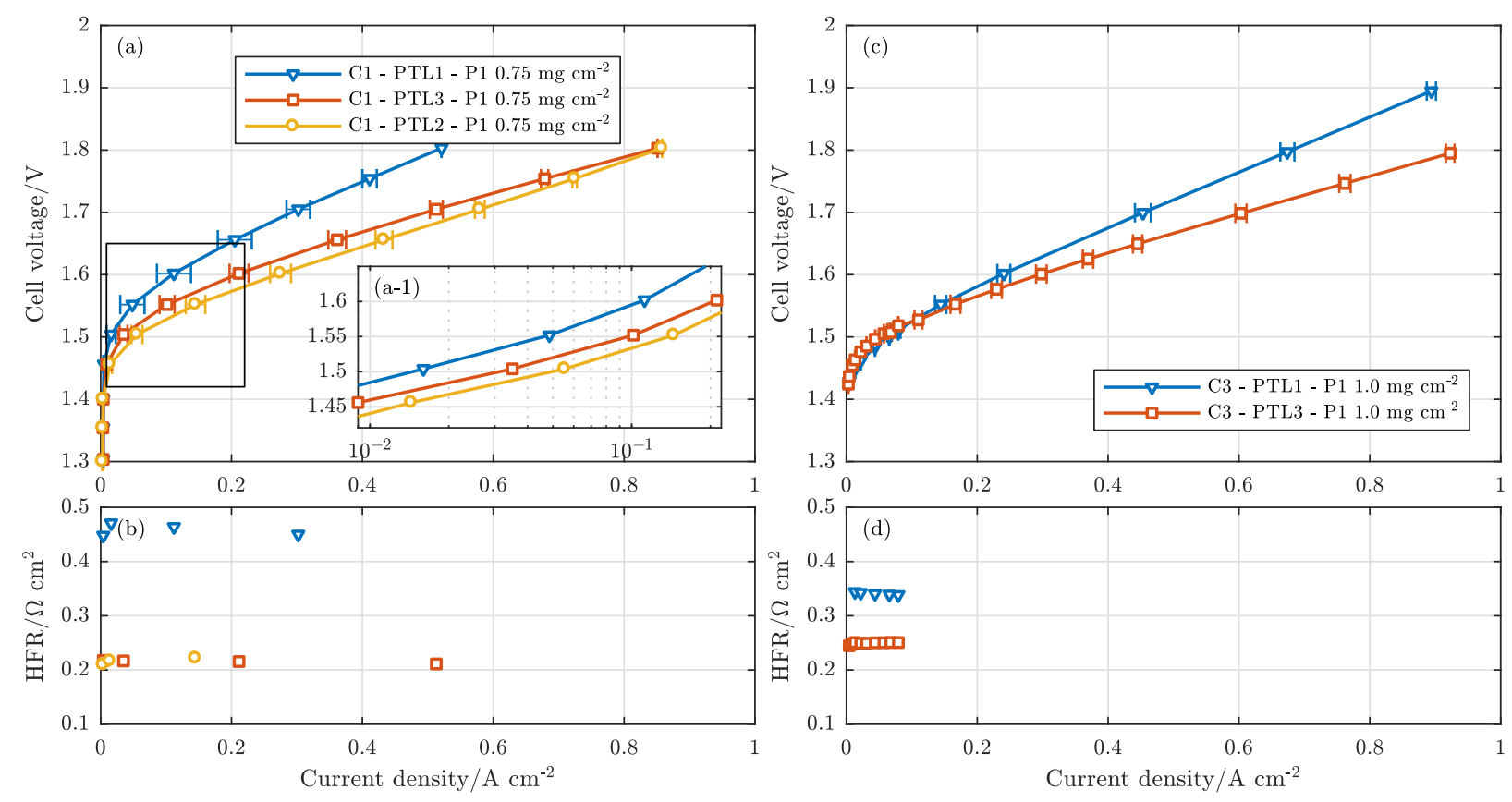

Fig. 3 Influences of PTL structure and treatment on cell performance (a) Polarization curves of CCMs measured with cell $C 1$ (a-1) insert: Cell voltage over logarithmic current density $\left(0.01 \mathrm{~A} \mathrm{~cm}^{-2} \leq i \leq 0.21 \mathrm{~A} \mathrm{~cm}^{-2}\right)$ for cell $C 1$. (b) HFR for PTL1 - PTL3 in cell C1 (c) Polarization curves of CCMs measured with cell C3 $\left(22.7 \mathrm{~cm}^{2}\right)$ with different PTL treatments and different PTL porosities. (d) HFR for cell C3 with PTL1 + PTL3; all measured at $60{ }^{\circ} \mathrm{C}$

\subsection{Influences of anode PTLs and its treatment}

The influence of the PTL's structural parameters and pretreatment procedure was studied in the differential and the elongated cell. Therefore, two types of PTLs were used: one type with a porosity of $50 \%$ and a fiber diameter of $20 \mu \mathrm{m}$ and the other type with a porosity of $80 \%$ and two different fiber diameters of $20 \mu \mathrm{m}$ and $45 \mu \mathrm{m}$. Due to the coupling of fiber diameter and porosity, two different structures were observed. As PTL pretreatment, the HCl-etching procedure was used. Initially, cell $C 1$ was equipped with the PTLs of different structure and with PTLs that were pretreated by the HCl-etching procedure (see table. 1).

The results of these measurements are shown in Fig. 3 (a,a-1) in the form of polarization curves. Fig. 3 (a) shows the polarization curve of the full current and the voltage range observed in these experiments, while the inset of Fig. 3 (a) shows a low current density range $\left(0.01 \mathrm{~A} \mathrm{~cm}^{-2} \leq i \leq 0.21 \mathrm{~A} \mathrm{~cm}^{-2}\right)$ in a semi-log plot presentation. The effects of activation overpotential dominate in this range.

The impact of PTL porosity and $\mathrm{HCl}$ treatment is observed in both the low as well as high current density range. In general, for the same PTL porosity $(\epsilon=$ $50 \%$ ), the PTL $\mathrm{HCl}$ treatment improves the overall electrolyzer performance. If HCl-treated PTLs of different porosities $(\epsilon=50 \%, \epsilon=80 \%)$ were compared, than only a very slight improvement of the lower porous PTL was detected at 
low current densities (see Fig. 3 (a-1)). With the untreated PTL1 in comparison to the treated PTL2 of equal porosity, the improvement could be attributed to an improved Ohmic contact. In contrast to the higher porous PTL3, PTL2 can provide this slight improvement due to a more adequate catalyst utilization at low current densities.

However, the resulting voltage difference for varied PTL porosities is minor in regions of low current densities $\left(\Delta U \leq 20 \mathrm{mV}\right.$ at $i \leq 0.2 \mathrm{~A} \mathrm{~cm}^{-2}$, see Fig. 3 (a-1)) and it is difficult to quantify because of the relatively high measurement uncertainty. For ranges of higher current densities the polarization curves PTL3 and PTL2 even converge and tend to intersect, which indicate that the structural properties, e.g., a higher porosity of the anode side PTL, can slightly influence for instance the mass transport. As literature confirms (Ito et al. measured differences of $15 \mathrm{mV} @ \approx 1.0 \mathrm{~A} \mathrm{~cm}^{-2}$ with comparable PTL properties [14]), the porosity effect on the performance is minor and can only be discussed for $\Delta U \leq 20 \mathrm{mV}-25 \mathrm{mV}$ but cannot serve as an explanation for divergences in the range of $\Delta U \geq 100 \mathrm{mV}$.

For a current density of $i=0.5 \mathrm{~A} \mathrm{~cm}^{-2}$, Fig. 3 (a) shows a voltage difference of $\Delta U \approx 120 \mathrm{mV}$ (respectively $\Delta U \approx 95 \mathrm{mV}$ ) between each HCL-treated and the untreated PTL. Voltage differences of this range can only be explained by an improvement of the Ohmic resistance at these current densities, which can be clearly seen in Fig. 3 (b). The high-frequency resistances (HFRs) of PTL2 and PTL3 are reduced by about $50 \%$ compared to the PTL1, and stay quite constant for all currents, which is attributed to the etching procedure. It is likely that the $\mathrm{HCl}$ treatment improves the contact between the catalyst layer and the PTL surface substantially by preventing it from passivation and by purifying the contact interfaces [13].

In the framework of this contribution, similar experiments were carried out with cell $C 3\left(22.7 \mathrm{~cm}^{2}\right)$. This cell was assembled with the untreated and little porous $(\epsilon=50 \%)$ anode PTL1 and additionally with the high porous and etched PTL3. Fig. 3 (c,d) show that the qualitative results are in good agreement with the results of the $4 \mathrm{~cm}^{2}$ cell (Fig. $3(\mathrm{a}, \mathrm{b})$ ). At a current density of $i=0.5 \mathrm{~A} \mathrm{~cm}^{-2}$ the cell voltage of the etched PTL is $\Delta U \approx 55 \mathrm{mV}$ lower than the untreated one and increases with higher current densities $\left(\Delta U \approx 120 \mathrm{mV} @ i=0.9 \mathrm{~A} \mathrm{~cm}^{-2}\right)$. This behaviour is similar to the polarization curves of PTL1 and PTL3 in the small cell, which also diverge with higher current densities (see Fig. 3 (a)). The Ohmic resistances in Fig. 3 (d) are also qualitatively similar. The etched PTL shows a clearly reduced Ohmic resistance which fits to the reduced slope of the polarisation curve. With the results from the smaller cell and literature (e.g., [14]), it is likely that the porosity effect, is not driving this strong divergence of the polarisation curves at higher current densities. The results support the explanation, that the PTL etching can significantly improve the cell performance and allows the comparison of cells equipped with PTLs of different porosities [13].

As a comparison of Fig. 3 (b) and (d) shows, there are quantitative differences in the HFRs of both cells. In case of the untreated PTL1 this is most likely caused by a more intense passivation of the Ti felt in cell $C 1$. Hence, the etching of the PTLs leads to a reduction and an alignment of the HFRs of both cells. The lower HFR for the etched Ti felts of cell $C 1$ compared to cell $C 3$ can be explained by an enhanced electrical contact which the gold-coated flow field of cell $C 1$ provides. 


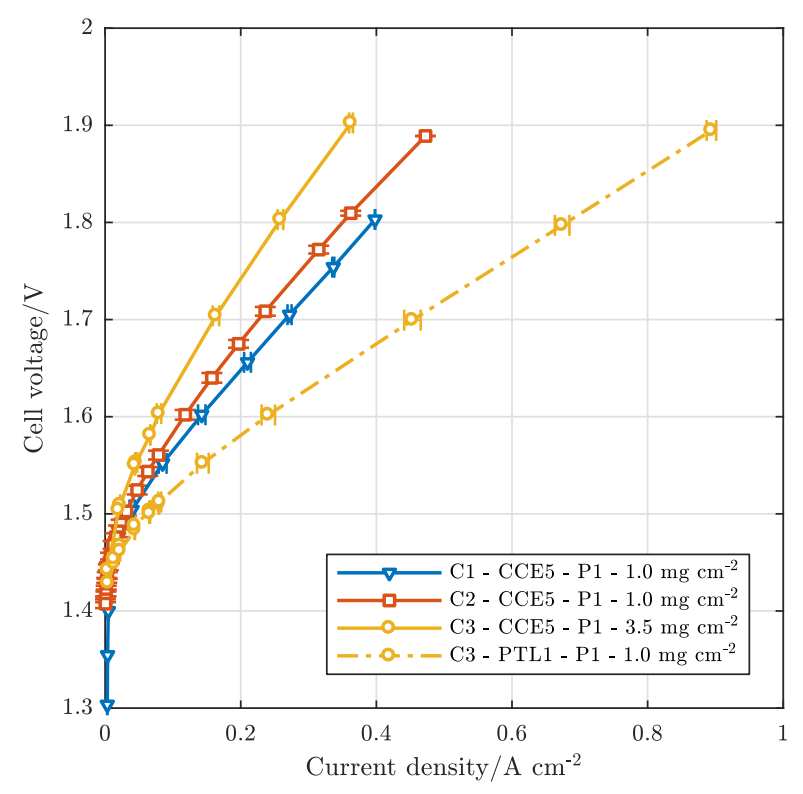

Fig. 4 Polarization curves of the CCEs concept measured with all three cells. Etched anode Ti felts deposited with Ir catalyst. Cathode side: commercial SGL graphite CCEs with PtC catalyst; additional: polarization curve of cell $C 3$ with a CCM (dashed line) compared to untreated PTL1

\subsection{Characterization of CCEs}

By using the catalyst-coated electrodes (CCEs), the issue regarding electrical contacting between catalyst layer and the PTL, which is present in the CCM concept, was meant to be reduced. Therefore, CCEs were prepared by spray coating the catalyst directly on the PTL materials (see Sec. 2.2). Fig. 4 illustrates the resulting polarization curves measured with the three cells equipped with CCEs and one CCM in cell C3 for comparison. Cells $C 1\left(4 \mathrm{~cm}^{2}\right.$, triangles) and C2 $\left(63.5 \mathrm{~cm}^{2}\right.$, rectangles) reached the best $\mathrm{CCE}$ performances. Both cells were assembled with CCEs of the same loading $\left(m_{\mathrm{IrO}_{2}}=1.0 \mathrm{mg} \mathrm{cm}^{-2}\right)$, while cell $C 3$ (circles) was prepared with a highly increased anode loading of $m_{\mathrm{IrO}_{2}}=3.5 \mathrm{mg} \mathrm{cm}^{-2}$. However, a clearly reduced performance can be determined for the CCE in cell $C 3$ compared to the other CCEs. In comparison to the CCM concept, all cells with CCEs cannot compete with CCMs in terms of performance.

Table 2 shows the HFRs for a CCM and a CCE assembled in cell C3. The Ohmic resistances are approximately doubled in case of the CCE concept, which can be addressed to the high loss in proton conductivity. Additionally, poor ionic contact between the membrane and the catalyst is likely when the catalyst is only pressed on the membrane but not directly sprayed on it. This suggests that the more effective electrical contacting between the catalyst and current collector is counteracted by losses in the ionic resistance. 

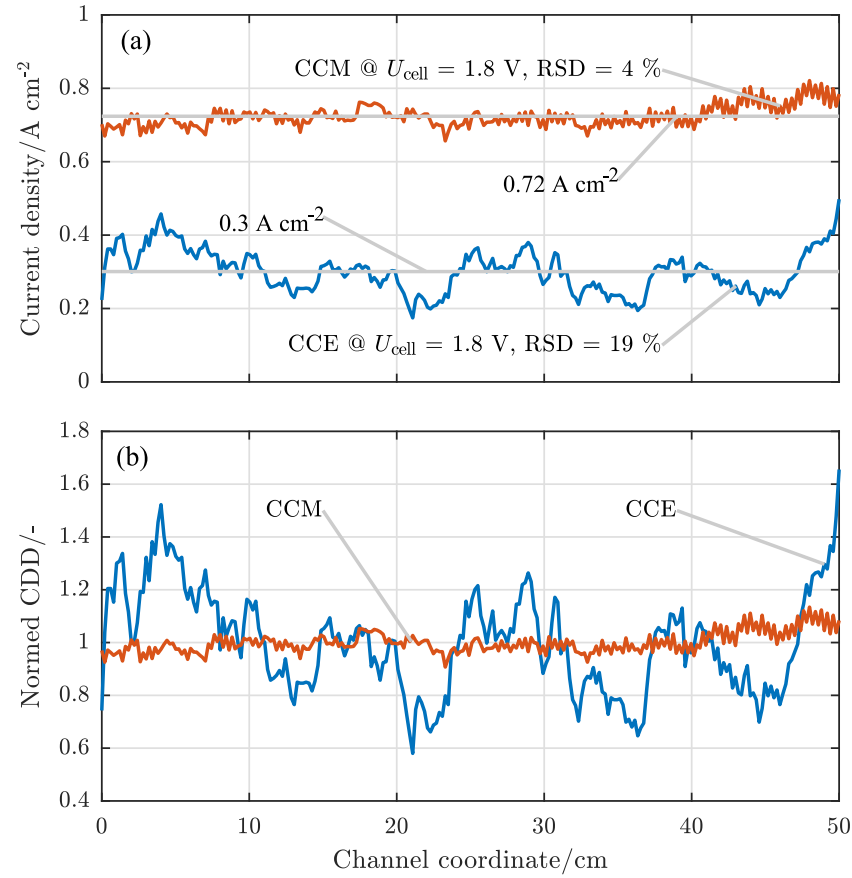

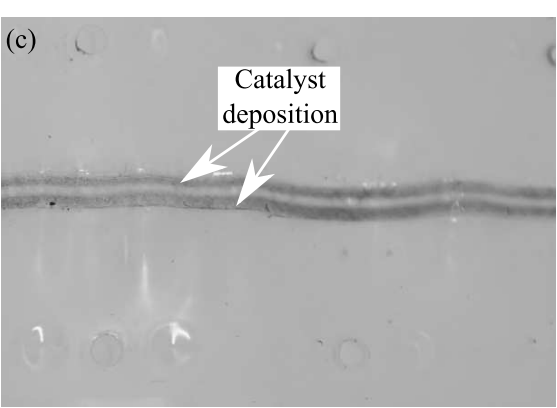

(d)

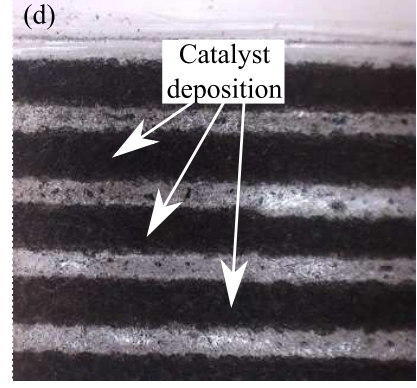

Fig. 5 Visualized contacting uncertainties with the CCE. (a) Current density distribution and (b) normalized current density distribution of the CCE and CCM measured with cell C3 $\left((50.4 \times 0.45) \mathrm{cm}^{2}\right)$; Photographs of Nafion ${ }^{\circledR}$ membranes after disassembling the CCEs for (c) cell $C 3$ and (d) cell $C 1$ showing catalyst deposition of the CCEs on the membrane especially along the lands

However, an additional problem is demonstrated in Fig. 5 (a), which could also serve as an explanation for the insufficient performance especially of the cell C3. Here, the current density distribution $(i(z))$ along the cell is shown for a CCM and a CCE under potentiostatic conditions. For a cell voltage of $U_{\text {cell }}=1.8 \mathrm{~V}$ the CCE reaches less than half of the CCM's mean current density (compare also with Fig. 4). Furthermore, the current density for the CCE forms a distinctly wavier and noisier profile. The noise of the profiles is represented mathematically by the relative standard deviation $R S D$, which is approximately $5 \times$ higher for the CCE than for the CCM $\left(R S D_{\mathrm{CCE}}=19 \%, R S D_{\mathrm{CCM}}=4 \%\right)$. Fig. 5 (b) illustrates this behavior. The normalized current density profile of the CCE shows outliers of up to $\pm 50 \%$, whereas the CCM shows maximal divergences from the mean value of approximately $\pm 15 \%$. These effects can be attributed to the poor contacting of the cathode CCE in cell C3. In the CCM setting of cell C3, a $1000 \mu \mathrm{m}$ Ti felt was used as the PTL for the cathode as well. Compared to this, the cathode graphite CCE of $300 \mu \mathrm{m}$ thickness is considerably thinner and unable to provide sufficient mechanical strength to contact equally along the cell.

Comparable poor performances of the CCEs as compared to the CCMs were discovered with the other cells as well. The possible explanations include the contacting problem between the membrane and catalyst layer, and catalyst utilization, 
which was identified after the disassembling of the cells. The photographs of the dissembled membrane of the $4 \mathrm{~cm}^{2}$ (Fig. 5 (c)) and the $22.7 \mathrm{~cm}^{2}$ cell (Fig. 5 (d)) indicate that the stable contacting between the membrane and catalyst might have only been reached along the lands but not along the channels. Both figures show that catalysts from the anode and cathode are deposited primarily along the lands. Consequently, this would imply that the contact pressure was sufficient only for approximately half of the active area for cell $C 1$ and $2 / 3$ for cell $C 3$. The area below the channels would not be active. A similar performance gap between CCM and CCE designs has been reported in fuel cell literature [15]. However, optimization of preparation methods and further research promise more comparable performances [16].

Table 2 High-frequency resistances of the $22.7 \mathrm{~cm}^{2}$ cell for CCE and CCM (with untreated, $\epsilon=50 \%$ PTL) at various current densities

\begin{tabular}{lcccc}
\hline \hline & $i / \mathrm{A} \mathrm{cm}^{-2}$ & 0.066 & 0.044 & 0.022 \\
$R_{\Omega} / \Omega \mathrm{cm}^{2}$ & & & \\
\hline $\mathrm{CCE}$ & 0.711 & 0.710 & 0.708 \\
$\mathrm{CCM}$ & 0.339 & 0.341 & 0.342 \\
\hline
\end{tabular}

\subsection{Comparison of all labs}

In addition to bilateral tests, triplet comparison of three CCMs is performed in Fig. 6. Herein, the catalyst loading of cells C2 and C3 are similar, while the CCM used in cell $C 1$ had a slightly lower anode Ir loading. The manufacturing processes of the CCMs are identical for cells $C 1$ and $C 3$ : they are both prepared with method P1, while the CCM for cell C2 was manufactured with P2. As the examination of the different preparation methods showed a sufficient agreement with regard to the polarization curves (see Fig. 2), these influences are considered negligible. Furthermore, different PTLs were used. PTL1 was used in cells $C 1$ and C3, whereas PTL4 was used for cell C2. All PTLs remained untreated, but the latter was of a different porosity and fiber diameter $(\epsilon=80 \%, 25 \mu \mathrm{m}-40 \mu \mathrm{m})$. The results from Fig. 3 (a) and literature indicate that these structural differences have only a minor influence on the performance of the cell (measured data: $\Delta U \leq$ $25 \mathrm{mV}$, literature: $\Delta U \leq 15 \mathrm{mV}[18]$ ), compared to the herein also investigated etching of the PTLs $\left(\Delta \bar{U} \approx 100 \mathrm{mV} @ i=0.5 \mathrm{~A} \mathrm{~cm}^{-2}\right)$. Especially for the higher current densities $\left(i>0.5 \mathrm{~A} \mathrm{~cm}^{-2}\right)$, the performance was essentially equal. A good comparison requires no temperature changes from all cells and no mass transport limitations. With regard to this ring experiment, this was realized by sufficient water fluxes on the anode $\left(\dot{m}_{\mathrm{H}_{2} \mathrm{O}}^{\mathrm{A}} \geq 1.5 \mathrm{ml} \mathrm{min}^{-1} \mathrm{~cm}^{-2}\right)$.

Polarization curves for the $63.5 \mathrm{~cm}^{2}$ (squares) and $22.7 \mathrm{~cm}^{2}$ (circles) cells in Fig. 6 (a) demonstrate a very effective agreement in the ranges of low current densities and only slight divergence with higher voltages (table 3 ). The polarization curve of cell $C 1,\left(4 \mathrm{~cm}^{2}\right)$ shows reduced performance, primarily due to the lower catalyst loading on the anode side. 


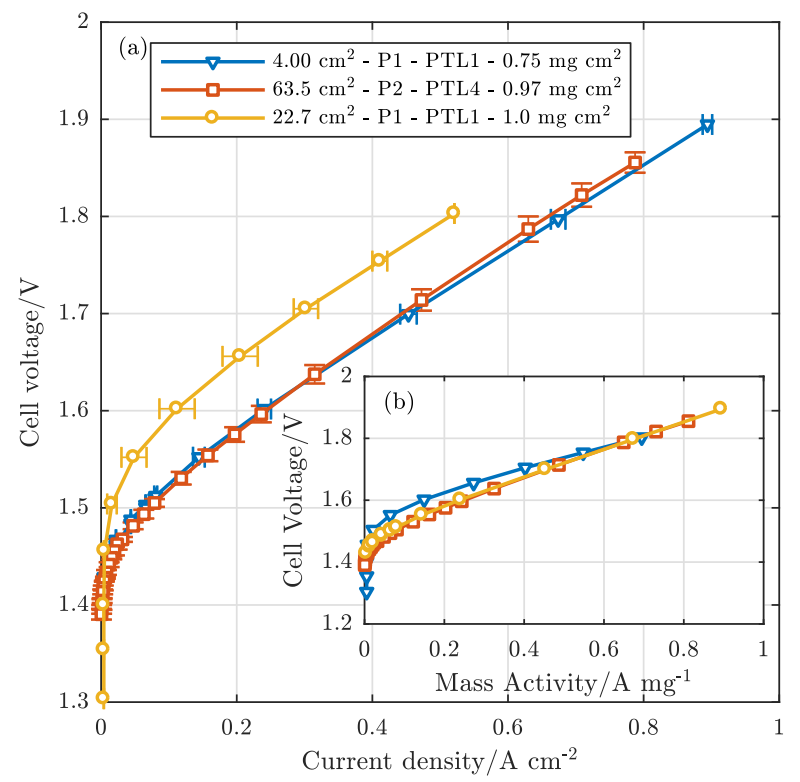

Fig. 6 Comparison of CCMs with all cells (a) Polarization curves for all with untreated PTLs (different porosities) and slightly different anode catalyst loadings; (b) Cell voltage as a function of mass activity $i / m_{\mathrm{IrO}_{2}}$ to reduce the effect of different loadings.

To consider the effect of different CCM loadings, Fig. 6 (b) shows a polarization curve with current density normalized by the Ir loading on the anode, further called mass activity $i / m_{\mathrm{IrO}_{2}}$. With this correction a sufficient agreement between all curves was achieved. In table 3 this can be seen quantitatively with a comparison of the mass activities at a cell voltage of $U_{\text {cell }}=1.8 \mathrm{~V}$. At this voltage, the divergences between all three cells are in the range of less than $7 \%$ of the mass activity. The simple division of the current density by the anode catalyst loading is only a first linear approach, which works well at higher voltages. For more detailed calculations, fuel cell literature suggests highly extended mathematical models (e.g., [17]).

This trilateral ring experiment supports on the one hand, that the generalization of certain observations (e.g., PTL etching, or poor ionic contacting with spray-coated CCE concept) is possible. On the other hand, these experiments prove that a sufficient accordance between two cells or among more cells (and lab-

Table 3 Current density $i$ and mass activity $i / m_{\mathrm{IrO}_{2}}$ for the three cell sizes @ $U_{\text {cell }}=1.8 \mathrm{~V}$

\begin{tabular}{lcccc}
\hline & & $4 \mathrm{~cm}^{2}$ & $63.5 \mathrm{~cm}^{2}$ & $22.7 \mathrm{~cm}^{2}$ \\
\hline$i$ & in $\mathrm{A} \mathrm{cm}^{-2}$ & 0.52 & 0.63 & 0.66 \\
$i / m_{\mathrm{IrO}_{2}}$ & in $\mathrm{A} \mathrm{mg}^{-1}$ & 0.69 & 0.65 & 0.66 \\
\hline
\end{tabular}


oratories) can be achieved, on the condition that the special features of the used materials, the test cell, and the test system are well known.

\section{Conclusion}

A ring experiment in different laboratories was realized to rate the comparability of different cell sizes assembled with similar materials. Therefore, the influence of differently treated PTLs of different structural properties, individually prepared $\mathrm{CCMs}$, and an alternative CCE design were studied and checked with regard to performances of different cell geometries. Despite the different CCM preparation methods, the measurements confirmed that at least the initial behavior represented by the polarization curves and the HFR show similar results and can therefore be generalized in the framework of this ring experiment. Etching was proven to be a promising pretreatment of the anode side of the PTLs. Tests with two different cells confirmed a strong reduction of Ohmic losses $\left(\Delta U_{\text {cell }}>100 \mathrm{mV} @ \approx 1.0 \mathrm{~A} \mathrm{~cm}^{-2}\right)$. In contrast, the effect of PTL's porosity, which is discussed in more detail in literature, shows only minor effects (less than $15 \mathrm{mV} @ \approx 1.0 \mathrm{~A} \mathrm{~cm}^{-2}[18]$ ), albeit only at high water flow rates. Therefore, sufficiently high water fluxes of $\dot{m}_{\mathrm{H}_{2} \mathrm{O}}^{\mathrm{A}} \geq$ $1.5 \mathrm{ml} \mathrm{min}^{-1} \mathrm{~cm}^{-2}$ were set in the herein presented experiments. An alternative CCE design could not reach the desired performance for all cells showing similar type of problems in all cell geometries, because of an inadequate contact between the CCEs and the membrane.

Generally, this contribution can serve as a first approach of a ring experiment, showing that the comparison of different materials in different cells can be a useful intermediate step for the translation of a macroscopic phenomenon to a stack level. Differences in material properties, system geometry, and material treatment need to be well known, but do not necessarily need to be in full accordance to allow qualitative and even quantitative comparison.

Acknowledgements The financial support by German Research Foundation (Deutsche Forschungsgemeinschaft, DFG) within the framework of the projects grants HA 6841/2-1 and SU 189/7-1 and the Grant Agency of the Czech Republic within the framework of the Project No. 15-02407J is gratefully acknowledged. GP, TVK and KS acknowledge strongly the financial support of MaxNetEnergy Network. The authors thank Ameya Krishna Bysani for carrying out the experiments at the MPI Magdeburg.

\section{References}

1. Buttler A, Spliethoff H Current status of water electrolysis for energy storage, grid balancing and sector coupling via power-to-gas and power-to-liquids: A review. Renewable and Sustainable Energy Reviews, in press (2017)

2. Rozain C, Mayousse E, Guillet N, Millet P Influence of iridium oxide loadings on the performance of PEM water electrolysis cells: Part I Pure IrO2-based anodes. Applied Catalysis B: Environmental, 182(Supplement C), 153 - 160 (2016)

3. Millet P, Mbemba N, Grigoriev S, Fateev V, Aukauloo A, Etivant C Electrochemical performances of PEM water electrolysis cells and perspectives. International Journal of Hydrogen Energy, 36(6), 4134 - 4142 (2011) 
4. Lee BS, Park HY, Choi I, Cho MK, Kim HJ, Yoo SJ, Henkensmeier D, Kim JY, Nam SW, Park S, Lee KY, Jang JH Polarization characteristics of a low catalyst loading PEM water electrolyzer operating at elevated temperature. Journal of Power Sources, 309(Supplement C), 127 - 134 (2016)

5. Fouda-Onana F, Chandesris M, Médeau V, Chelghoum S, Thoby D, Guillet N Investigation on the degradation of MEAs for PEM water electrolysers part I: Effects of testing conditions on MEA performances and membrane properties. International Journal of Hydrogen Energy, 41(38), 16,627 - 16,636 (2016)

6. Fallisch A, Schellhase L, Fresko J, Zechmeister M, Zedda M, Ohlmann J, Zielke L, Paust N, Smolinka T Investigation on PEM water electrolysis cell design and components for a HyCon solar hydrogen generator. International Journal of Hydrogen Energy, 42(19), 13,544 - 13,553 (2017)

7. Verdin B, Fouda-Onana F, Germe S, Serre G, Jacques P, Millet P Operando current mapping on PEM water electrolysis cells. Influence of mechanical stress. International Journal of Hydrogen Energy, 42(41), 25,848 - 25,859 (2017)

8. Trinke P, Bensmann B, Hanke-Rauschenbach R Current density effect on hydrogen permeation in PEM water electrolyzers. International Journal of Hydrogen Energy, 42(21), 14,355 - 14,366 (2017)

9. Ito H, Miyazaki N, Ishida M, Nakano A Cross-permeation and consumption of hydrogen during proton exchange membrane electrolysis. International Journal of Hydrogen Energy, 41(45), 20,439 - 20,446 (2016)

10. Danilovic N, Ayers KE, Capuano C, Renner JN, Wiles L, Pertoso M (Plenary) Challenges in Going from Laboratory to Megawatt Scale PEM Electrolysis. ECS Transactions, 75(14), 395-402 (2016)

11. Mališ J, Mazúr P, Paidar M, Bystroň T, Bouzek K Nafion 117 stability under conditions of PEM water electrolysis at elevated temperature and pressure. International Journal of Hydrogen Energy, 41(4), 2177 - 2188 (2016)

12. Krýsa J, Kule L, Mráz R, Roušar I Effect of coating thickness and surface treatment of titanium on the properties of $\mathrm{IrO} 2-\mathrm{Ta} 2 \mathrm{O} 5$ anodes. Journal of Applied Electrochemistry, 26(10), 999-1005 (1996)

13. Bystroň T, Paidar M, Bouzek K Enhancing PEM water electrolysis efficiency by reducing the extent of Ti gas diffusion layer passivation. Journal of Applied Electrochemistry, submitted (2017)

14. Ito H, Maeda T, Nakano A, Kato A, Yoshida T Influence of pore structural properties of current collectors on the performance of proton exchange membrane electrolyzer. Electrochimica Acta, 100(Supplement C), 242 - 248 (2013)

15. Sung CC, Liu CY, Cheng CC Performance improvement by a glue-functioned Nafion layer coating on gas diffusion electrodes in PEM fuel cells. International Journal of Hydrogen Energy, 39(22), 11,700 - 11,705 (2014)

16. Klingele M, Breitwieser M, Zengerle R, Thiele S Direct deposition of proton exchange membranes enabling high performance hydrogen fuel cells. J Mater Chem A, 3, 11,239-11,245 (2015)

17. Neyerlin KC, Gu W, Jorne J, Gasteiger HA Determination of Catalyst Unique Parameters for the Oxygen Reduction Reaction in a PEMFC. Journal of The Electrochemical Society, 153(10), A1955-A1963 (2006)

18. Ito H, Maeda T, Nakano A, Hwang CM, Ishida M, Kato A, Yoshida T Experimental study on porous current collectors of PEM electrolyzers. International Journal of Hydrogen Energy, 37(9), 7418 - 7428 (2012) 